\title{
Lingula and Antilingula as Anatomic Reference Points for Ramus Osteotomies
}

\author{
Deepika Chenna ${ }^{1}$, Mamatha Hosapatna ${ }^{1}$, Antony Sylvan D’Souza ${ }^{1}$, Srikanth Gadicherla ${ }^{2}$, \\ Kalyana Chakravarthy Pentapati ${ }^{3, *}$ \\ ${ }^{1}$ Department of Anatomy, Kasturba Medical College, Manipal, Manipal University \\ ${ }^{2}$ Department of Oral and Maxillofacial Surgery, Manipal College of Dental Sciences, Manipal University, Manipal \\ ${ }^{3}$ Department of Public Health Dentistry, Manipal College of Dental Sciences, Manipal University, Manipal \\ *Corresponding author: drkalyan81@gmail.com
}

Received December 11, 2014; Revised December 25, 2014; Accepted December 30, 2014

\begin{abstract}
Aim: To evaluate the role of lingula and antilingula as landmark to guide the oral surgeons. Methods: A total of 50 mandibles (100 sides) were available for evaluating the lingula and antilingula. Four measurements (W, $\mathrm{X}, \mathrm{Y}$ and $\mathrm{Z}$ ) were recorded for the mandibular foramen, lingula and antilingula in 2 planes (horizontal and vertical) by single trained calibrated examiner. Results: Only 52 sides had palpable antilingula, hence the comparisons with respect to antilingula and mandibular foramen were done for only 52 sides. The mean values measured were significantly lower for lingula with respect to $\mathrm{Y}$ and $\mathrm{W}$ points while it was significantly higher with respect to $\mathrm{X}$ and $\mathrm{Z}$ points when compared to mandibular foramen. Antilingula also showed similar trend when compared to mandibular foramen. Conclusion: Lingula can be used as landmark to avoid the mandibular foramen to perform ramus osteotomies. Antilingula if palpable can be used as supplementary landmark for the same. With respect to both the landmarks, mandibular foramen is located posterioinferiorly.
\end{abstract}

Keywords: foramen, lingual, antilingula, mandible, Sagittal split ramus osteotomy

Cite This Article: Deepika Chenna, Mamatha Hosapatna, Antony Sylvan D’Souza, Srikanth Gadicherla, and Kalyana Chakravarthy Pentapati, "Lingula and Antilingula as Anatomic Reference Points for Ramus Osteotomies.” International Journal of Dental Sciences and Research, vol. 3, no. 1 (2015): 1-3. doi: 10.12691/ijdsr-3-1-1.

\section{Introduction}

Orthognathic surgeries are common surgical procedures performed to correct skeletal malocclusion. One such procedure which is widely used by oral and maxillofacial surgeons is sagittal split ramus osteotomy which was first proposed by Schuchardt in 1942. [1] This procedure involves the surgical repositioning of mandible with many added advantages like intra-oral approach, broad bone interface, the possibility of rigid internal fixation and early jaw function. [2] Landmarks like lingula and antilingula were suggested as reference marks for the surgeons to correctly identify mandibular foramen due to their close approximation to the inferior alveolar nerve. [2-11].

Many studies have shown the usefulness and success rate of lingula in identifying the mandibular foramen for safely performing surgeries without potential nerve injuries. [2-7] However, equivocal results were shown with respect to antilingula. $[2,8,9,10,11]$ Some researchers suggested that the antilingula is an expression of mandibular foramen[12-14]and surgeries can safely be performed superiorly and posteriorly without the risk of nerve injury while others reported that an incidence of up to $30 \%$ nerve injuries when antilingula was used as the landmark. [8,15,16,17].
The controversial results in the literature might be due to racial differences in expression of the landmarks, growth patterns, examiner variations or study of dried skulls which may be worn out. Due to the lack of substantial evidence and equivocal results in the literature we aimed to evaluate the role of lingula and antilingula as landmark to guide the oral surgeons.

\section{Materials and Methods}

We conducted a study to evaluate lingula and antilingula in human cadaver dry mandibles. A total of 50 mandibles (100 sides) were available for evaluating the lingula and antilingula. A single trained and calibrated examiner conducted all the recordings. Identification of antilingula was identified with prior palpation. Measurements of the mandibular foramen, lingula and antilingula were taken in 2 planes (horizontal: $\mathrm{X}$ and Y; vertical: $\mathrm{W}$ and $\mathrm{Z}$ ) as suggested previously by Monnazzi et al. [2] W is the distance between the lower point of the mandibular foramen/lingula/antilingula points to the mandibular base in a vertical straight line; $\mathrm{Z}$ is the distance from these points to the lower point of thesigmoid notch. $\mathrm{X}$ is the distance from the most anterior part of the mandibular foramen/lingula/antilingula points to the anterior border of themandibular ramus; $\mathrm{Y}$ is 
thedistance from these points to the posterior border of themandibular ramus (Figure 1 and Figure 2). All the measurements were made using digital Vernier calipers. All the analysis was done using SPSS version 14. A pvalue of $<0.05$ was considered statistically significant. Comparison of mean values was done using paired t test. Intra-examiner reliability was calculated (Pearson correlation coefficient) for 10 samples and was shown to be 0.98 (excellent agreement).

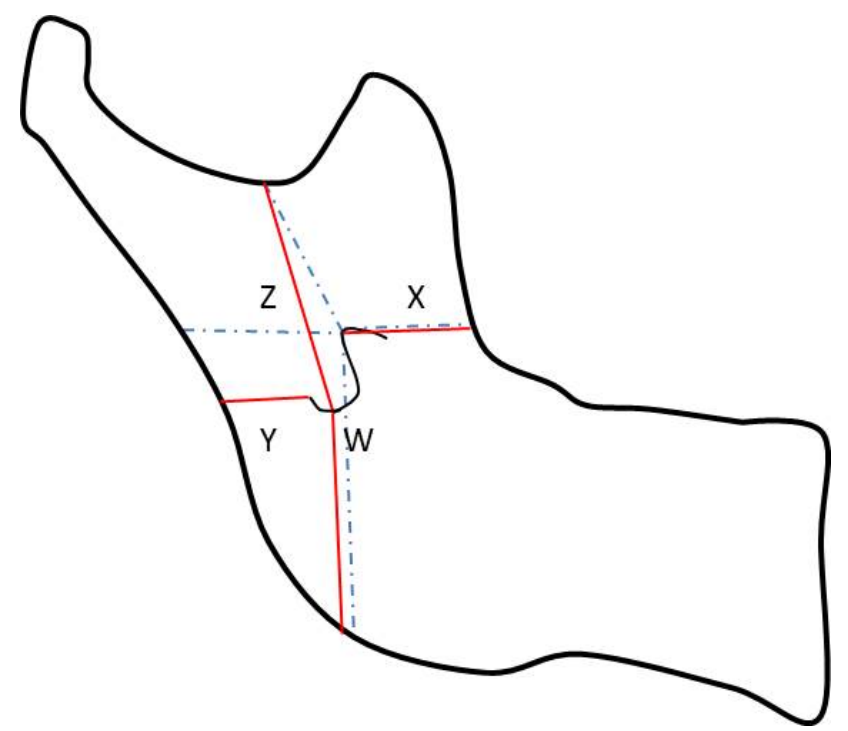

Figure 1. Measured reference points for mandibular foramen (Continuous line) and Lingula spots (Dotted lines)

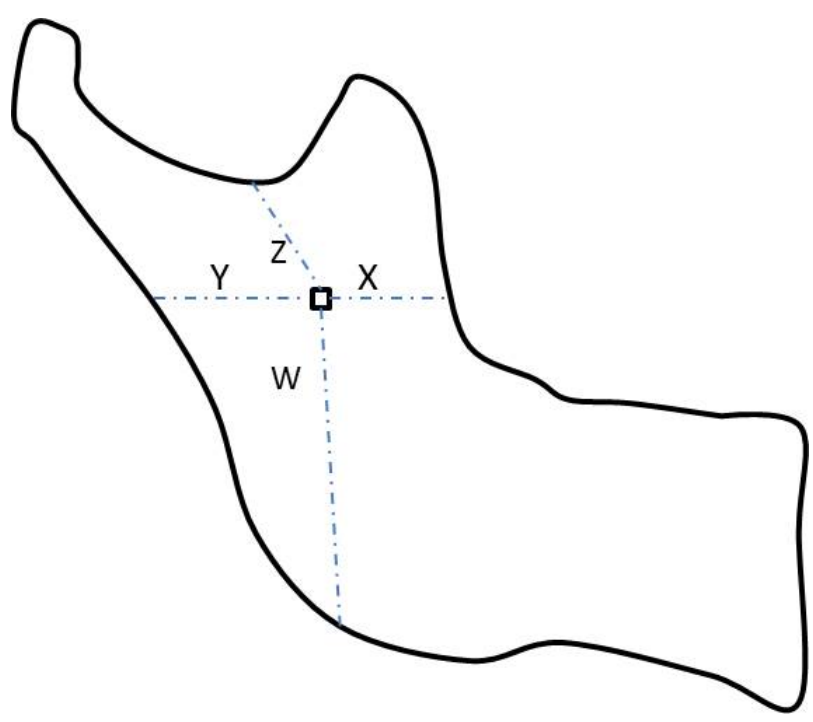

Figure 2. Measured reference points for antilingula spots (Dotted lines)

\section{Results}

A total of 50 cadaveric dried mandibles (100 sides) were evaluated for mandibular foramen, lingula and antilingula. Only 52 sides had palpable antilingula, hence the comparisons with respect to antilingula and mandibular foramen were done for only 52 sides. The mean values measured were significantly lower for lingula with respect to $\mathrm{Y}$ and $\mathrm{W}$ points while it was significantly higher with respect to $\mathrm{X}$ and $\mathrm{Z}$ points when compared to mandibular foramen (Table 1). Antilingula also showed similar trend when compared to mandibular foramen (Table 2).

Table 1. Comparison of mean $\mathrm{X}, \mathrm{Y}, \mathrm{W}$ and $\mathrm{Z}$ between mandibular foramen and lingula

\begin{tabular}{cccccc}
\hline & $\begin{array}{c}\text { Mandibular Foramen } \\
\text { Mean } \pm \text { SD }\end{array}$ & $\begin{array}{c}\text { Lingula } \\
\text { Mean } \pm \text { SD }\end{array}$ & N & $\begin{array}{c}\text { Mean difference } \\
\text { Mean } \pm \text { SD }\end{array}$ & p-value \\
\hline $\mathrm{X}$ & $17.13 \pm 2.77$ & $16.37 \pm 2.51$ & 100 & $0.76 \pm 1.63$ & $<0.001$ \\
$\mathrm{Y}$ & $11.35 \pm 2.14$ & $15.36 \pm 2.18$ & 100 & $-4.01 \pm 1.99$ & $<0.001$ \\
$\mathrm{Z}$ & $22.38 \pm 3.54$ & $15.00 \pm 2.78$ & 100 & $7.38 \pm 2.48$ & $<0.001$ \\
$\mathrm{~W}$ & $23.41 \pm 4.19$ & $31.58 \pm 4.46$ & 100 & $-8.17 \pm 3.31$ & $<0.001$ \\
\hline
\end{tabular}

Table 2. Comparison of mean $\mathrm{X}, \mathrm{Y}, \mathrm{W}$ and $\mathrm{Z}$ between mandibular foramen and antilingula

\begin{tabular}{lccccc}
\hline & $\begin{array}{c}\text { Mandibular Foramen } \\
\text { Mean } \pm \text { SD }\end{array}$ & $\begin{array}{c}\text { Anti-Lingula } \\
\text { Mean } \pm \text { SD }\end{array}$ & $\mathrm{N}$ & $\begin{array}{c}\text { Mean difference } \\
\text { Mean } \pm \text { SD }\end{array}$ & p-value \\
\hline $\mathrm{X}$ & $17.38 \pm 2.94$ & $15.79 \pm 2.52$ & 52 & $1.60 \pm 2.58$ & $<0.001$ \\
$\mathrm{Y}$ & $11.67 \pm 2.27$ & $15.87 \pm 2.17$ & 52 & $-4.19 \pm 2.01$ & $<0.001$ \\
$\mathrm{Z}$ & $22.67 \pm 3.03$ & $13.48 \pm 2.11$ & 52 & $9.19 \pm 2.98$ & $<0.001$ \\
$\mathrm{~W}$ & $24.25 \pm 4.03$ & $33.29 \pm 3.93$ & 52 & $-9.04 \pm 3.59$ & $<0.001$ \\
\hline
\end{tabular}

\section{Discussion}

Our study evaluated the applicability of lingula and antilingula as surgical landmark for orientation of mandibular foramen. It was seen that lingula and antilingula measurements were significantly different when compared to mandibular foramen. Our results suggested that the mandibular foramen was posterior to the lingula and antilingula when measured from the anterior border of the ramus in horizontal plane. Lingula and antilingula were located superiorly when compared to mandibular foramen. Similar result was reported by Monazzi et al. [2] However, these reference points could be useful only when the landmarks are palpable. Pogrel et al., [8] reported that they had identified antilingula in all the specimens while Monazzi et al., [2] reported that antilingual was not palpable on 15 sides out of 88 sides studied. Yates et al., [9] and Martone et al., [18] also reported that antilingula was not palpable in all the specimens. Our study was consistent with literature in which $48 \%$ of the specimens did not have palpable antilingula.

In our study, it was seen that mandibular foramen is located posterioinferior in relation to lingula and antilingula. This was consistent with literature which reported the same. There exists a large discrepancy in the mean values which were reported in the literature but in our study it was seen that mandibular foramen was 1.6 $\mathrm{mm}$ posterior and $9 \mathrm{~mm}$ inferior to the antilingula. Similarly, it was seen that mandibular foramen was 0.76 $\mathrm{mm}$ posterior and $8 \mathrm{~mm}$ inferior to the lingula. We suggest that the antilingula could be only supplementary landmark along with lingula and cannot be used solely as main landmark for performing osteotomies in mandibular areas. Hogan and Ellis [19] suggested that antilingula cannot be reliable landmark and is more related to musculotendinous apparatus than to the entrance of inferior alveolar nerve. Based on the results of our study we can conclude that lingula can be used as landmark to avoid the mandibular foramen to perform ramus osteotomies. Antilingula if palpable can be used as supplementary landmark for the same. With respect to both the landmarks, mandibular foramen is located posterioinferiorly. 


\section{Acknowledgments}

The authors did not receive any outside funding or grants.

\section{Conflict of Interest}

The authors declare that they have no conflict of interest.

\section{References}

[1] Schuchardt K. Ein Betrag Zur Chiurgischen Käieferorthopdie unter Berucksichtigung ihrer Bedeutung fur die Behandlung angeborener und erworbener Kieferdeformita"ten bei Soldaten. Dtsch Zahn Mund Keiferheil 9: 73-891942.

[2] Monnazzi MS, Passeri LA, Gabrielli MF, Bolini PD, de Carvalho WR, da Costa Machado H. Anatomic study of the mandibular foramen, lingula and antilingula in dry mandibles, and its statistical relationship between the true lingula and the antilingula. Int J Oral Maxillofac Surg 41: 74-82012.

[3] Jansisyanont P, Apinhasmit W, Chompoopong S. Shape, height, and location of the lingula for sagittal ramus osteotomy in Thais. Clin Anat 22:787-932009.

[4] Findik Y, Yildirim D, Baykul T. Three-dimensional anatomic analysis of the lingula and mandibular foramen: a cone beam computed tomography study. J Craniofac Surg 25: 607-102014.

[5] Park KR, Kim SY, Kim GJ, Park HS, Jung YS. Anatomic study to determine a safe surgical reference point for mandibular ramus osteotomy. J Craniomaxillofac Surg 42: 22-72014.

[6] Kay LW. Some anthropologic investigations of interest to oral surgeons. Int J Oral Surg 3: 363-79 1974.

[7] Kositbowornchai S, Siritapetawee M, Damrongrungruang T, Khongkankong W, Chatrchaiwiwatana S, Khamanarong K, Chnathaooplee T. Shape of the lingula and its localization by panoramic radiograph versus dry mandibular measurement. Surg Radiol Anat 29: 689-94 2007.

[8] Pogrel MA, Schmidt BL, Ammar A. The presence of the antilingula and its relationship to the true lingula. $\mathrm{Br} \mathrm{J}$ Oral Maxillofac Surg 33: 235-328 1995.

[9] Yates C, Olson D, Guralnick W. The antilingula as an anatomic landmark in oral surgery. Oral Surg Oral Med Oral Pathol 41: 705-8 1976.

[10] Langston JR, Tebo HG. The incidence and relationship of the lateral ramus prominence to the mandibular foramen. Oral Surg Oral Med Oral Pathol 44: 190-6 1977.

[11] Aziz SR, Dorfman BJ, Ziccardi VB, JanalM. Accuracy of using the antilingula as a sole determinant of vertical ramus osteotomy position. J OralMaxillofac Surg 65: 859-62 2007.

[12] Caldwell JB, Letterman GS. Vertical osteotomy in the mandibular rami for correction of prognathism. J Oral Surg 12: 185-202 1954.

[13] Gabriel AC. Some anatomical features of the mandible. J Anat 92: 580-6 1958.

[14] Hall HD, McKenna SJ. Further refinement and evaluation of intraoral vertical ramus osteotomy. J Oral Maxillofac Surg 45: 684-8 1987.

[15] Fontoura RA, Vasconcellos HA, Campos AES. Morphologic basis for the intraoral vertical ramus osteotomy: anatomic and radiographic localization of the mandibular foramen. J Oral Maxillofac Surg 60: 660-5 2002.

[16] Fujimura K, Segami N, Kobayashi S. Anatomical study of the complications of intraoral vertico-sagittal ramus osteotomy. J Oral Maxillofac Surg 64: 384-9 2006.

[17] Westermark A. Inferior alveolar nerve function after sagittal split osteotomy of the mandible: correlation with degree of intraoperative nerve encounter and other variables in 496 operations. Br J Oral Maxillofac Surg 36: 429-33 1998.

[18] Martone CH, Ben Josef AM, Wolf SM, Mintz SM. Dimorphic study of surgical anatomic landmarks of the lateral ramus of the mandible. Oral Surg Oral Med Oral Pathol Oral Radiol 75: 4364381993.

[19] Hogan G, Ellis E. The "antilingula"-fact or fiction? J Oral Maxillofac Surg 64: 1248-1254 2006. 